\title{
Challenges in Incorporating Electric Vehicles to Mitigate Greenhouse Gas Emissions
}

\author{
Milad Zokaei Ashtiani \\ University of Washington
}

\section{ABSTRACT}

An indisputable fact about our planet is that its atmospheric temperature has risen dramatically during the past century. Combustion of fossil fuels and their subsequent greenhouse gas emissions are thought to be the main contributors to recent changes within the Earth's ecosystem. The transportation sector and electricity generating power plants are each responsible for approximately one-third of these emissions. Shifting towards a cleaner and renewable resources to generate electricity is believed to omit a big portion of polluting substances.

Improvements in vehicles' fuel efficiency and the introduction of alternative fuels besides strategic plans to control travel demand are among the most promising approaches to alleviate emissions from the transportation sector. Recent technology advancements, however, drew much attention to the production and manufacturing of alternative fuel vehicles, electric vehicles in particular. Since these vehicles use electricity as part of or all their powertrain, assessing the amount of emissions they produce is closely tied to the cleanliness of the electricity source.

In order for a valid comparison to be made between internal combustion and electric vehicles, hence, a life cycle assessment procedure needs to be followed from production stages to terminal life of vehicles. Involvement of numerous affecting factors during the lifetime of a vehicle on one hand, and the ambiguity in the exact source of electricity used to charge electric vehicles on the other hand bring about more complexities. The latter case is more commonly known as the marginal grid problem, which deals with how a combination of sources used to generate electricity can influence the life cycle emissions.

There are also other concerns regarding the growth in fuel-efficient and electric vehicles. Transportation planners argue that new developments in the vehicle industry may attract more people to owning and driving cars. This phenomenon which is better known as a rebound effect not only will result in increased traffic congestion, but it can also outpace the environmental benefits from utilizing electric vehicles. Moreover, since fuel taxes comprise the majority of Highway Trust Funds, alternative ways to compensate for state and federal revenues should be devised. 
This paper is an attempt to review the existing literature to better elaborate on the role of the transportation sector in controlling climate change threats. More specifically, issues around the use of electric vehicles and how they can contribute to more environmentally friendly communities are discussed.

\section{INTRODUCTION}

With an increase in average global temperature, the Earth's ecology has undergone drastic changes. Despite some skeptics denying the relation of greenhouse gas (GHG) emissions level to the occurrence of recent changes in our planet, strong scientific evidence exists to support this fact. The movement towards cleaner energy consumption is the key to sustain current GHG levels. Because of the cumulative nature of GHG levels, actions taken in the past and present will directly affect the future of our next generations. Common GHGs that impact our planet by trapping sunlight heat include carbon dioxide, methane, nitrous oxide, ozone, water vapor, and chlorofluorocarbons (USDOT, 2010). Apart from GHGs, there are also other local and regional pollutants affecting human health such as Sulphur dioxide, nitrogen oxides, and particulate matter (Van Mierlo, et al., 2017).

According to the U.S. Energy Information Administration (EIA), two-thirds of energy consumption in the U.S. is attributed to electricity production and transportation sectors (EIA, 2017). The U.S. Environmental Protection Agency (EPA) reported in 2015 that electricity generation and transportation emitted 29\% and $27 \%$ of the total GHG, respectively (EPA, 2015). However, shifting from coal to cleaner sources of energy such as hydro, wind, solar, natural gas, nuclear power, etc., is believed to cut a great portion of emissions coming from electricity production.

On the other hand, the U.S. transportation sector consumed $92 \%$ of its driving force from petroleum-based fuels in 2016 (see Figure 1). Nearly $83 \%$ of the total GHG were emitted from on-road vehicles, i.e. 60\% from Light Duty Vehicles (LDVs), and the remaining from Medium- and Heavy- Duty Trucks (MDTs and HDVs) (EIA, 2017). The transportation sector takes even a greater part in states where electricity generation is based more on renewables and less emitting resources. In Washington State, transportation is responsible for $45 \%$ of the total GHG emissions, and this number goes higher to 50\% for the Puget Sound region (PSRC, 2010). This remarkable share of transportation in GHG emissions in the state of Washington can be explained in part due to the heavy use of hydropower for electricity generation.

Europe has similar status to the U.S. in energy consumption and GHG emissions from the transportation sector. Nearly one-third of total energy is consumed for transportation purposes that accounts for about a quarter of the total carbon dioxide 
emissions, from which more than $70 \%$ is associated with road transport (Van Mierlo, et al., 2017). Globally, 23\% of the transportation sector's carbon dioxide emits from fuel combustion with road transport responsible for three-quarters of these emissions. In 2010, LDVs represented $41 \%$ of total transport emissions globally (Palencia, et al., 2017). Therefore, a revolution in personal car technology and usage seems necessary for controlling the adverse effects of GHGs on the environment.

In this regard, several future GHG reduction targets are currently under discussion both in the U.S. and globally. To stay within a threshold of $2^{\circ} \mathrm{C}$ increase in average-

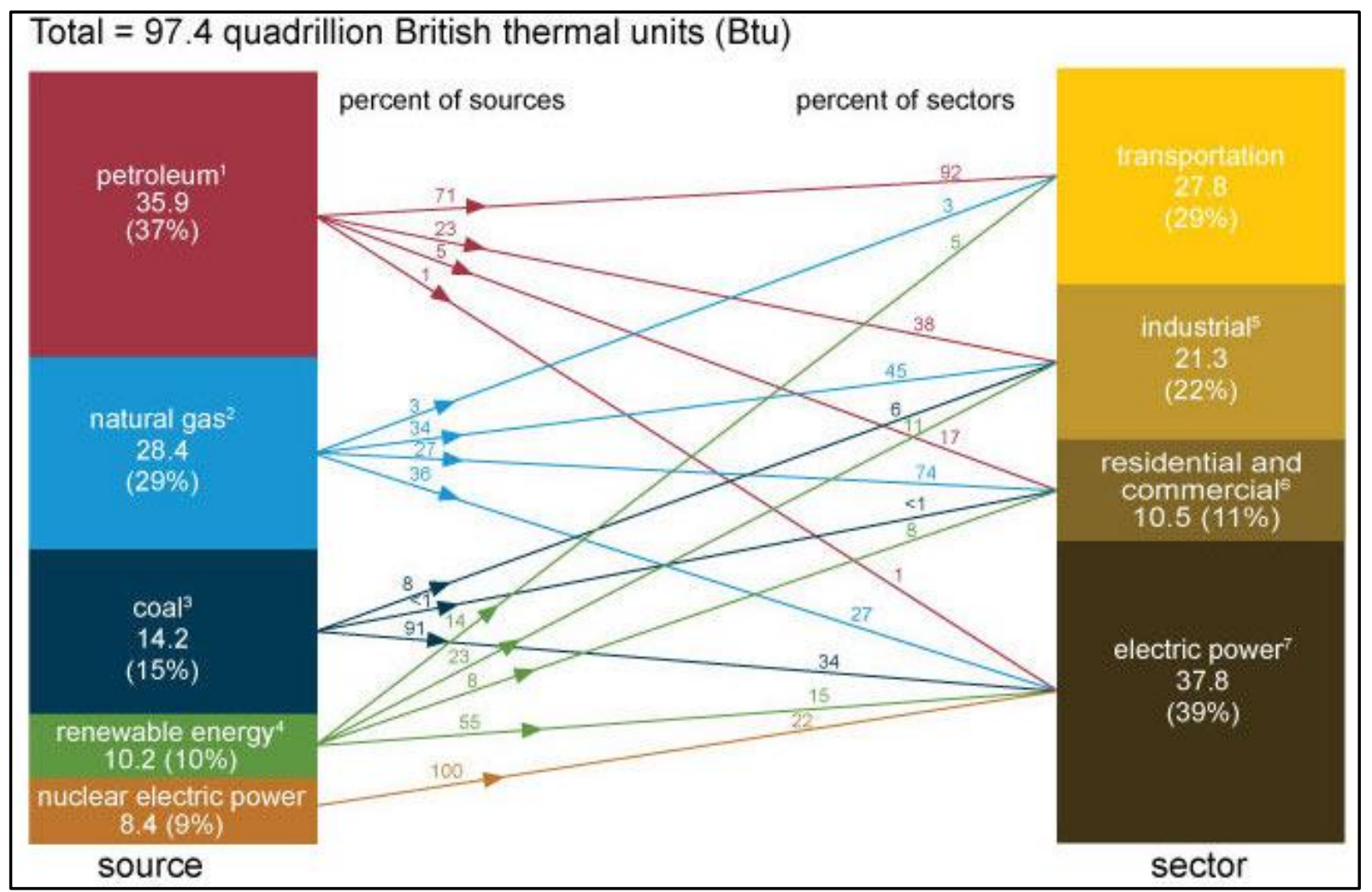

Figure 1 - U.S. primary energy consumption by source and sector in 2016 (EIA, 2017)

global temperature, GHG emissions should be reduced by as much as $80 \%$ from 2005 levels by 2050 (USDOT, 2010). On a global scale, limitations set for GHGs to reduce to $80 \%$ of 1990 levels by 2050 (Anair \& Mahmassani, 2012). Although there seems to be no unanimous agreement on the details of these GHG reduction goals, the general trend is uncontroversial. Each local government might pursue these targets differently; as an example, Washington State legislators in 2007 established the following limiting targets on the future state-wide GHG emissions as of RCW 70.235 .020 (PSRC, 2010): reduce to 1990 level by 2020; 25\% below 1990 level by 2035; and 50\% below 1990 level by 2050 .

This paper will focus on the role of the transportation sector in seeking GHG reduction targets. A summary of direct and indirect strategies that can be followed 
within the transportation sector will be discussed highlighting the new advancements in vehicle and fuel technology and the challenges involved.

\section{GHG REDUCTION STRATEGIES}

There are generally two broad approaches to alleviate transport-related GHG emissions. One is regarded as improvements relevant to vehicle performance, including fuel efficiency and alternative less polluting fuels such as electricity, hydrogen, and natural gas. Reliance solely on cleaner vehicles imposes a serious problem which is best known as induced demand or rebound effect. In that, improved vehicle performance would lower the relative costs of driving and in turn may cause users to drive more (Moore, et al., 2010; USDOT, 2010).

As a result of more people encouraged to drive, a higher vehicle mile traveled (VMT) may outperform the benefits from improved vehicle technology (PSRC, 2010; Litman, 2013; Langer, et al., 2017). For this reason, a second perspective to reducing GHG from the transportation sector is through controlling travel demand, also known as mobility management strategies. Reducing GHG within transportation, therefore, would require a social awareness in how we live, think, travel, and the way we define mobility (Climate Action Team, 2008).

\subsection{Comprehensive Evaluation}

In order to identify the absolute optimal solutions to tackle the share of transportation in the climate change phenomenon, a comprehensive approach needs to be considered. As transport policy options tend to have very diverse impacts than other sectors, a thorough analysis of all the parameters involved is required to seek certain objectives (Litman, 2013; NREL, 2015). In opposed to vehicle performance and energy consumption metrics which are fairly easier to measure, co-benefits derived from mobility management strategies are harder to quantify. Being difficult to measure, however, would not mean that their influences are negligible. An integrated plan that takes into consideration smarter mobility solutions along with improved vehicle performance is believed to reach the ultimate goals of reducing GHG and enriching society's well-being (Ma, et al., 2012).

The U.S. Department of Transportation outlined a comprehensive approach via the transportation sector in a rigorous study (USDOT, 2010). This pack of four solutions is: 1) introduction of less-emitting fuels, such as ethanol, natural gas, liquefied petroleum gas, hydrogen, and electricity; 2) improve vehicle fuel efficiency via advanced engine and transmission designs and lightweight materials; 3) increase transportation system efficiency by enhancing traffic flow and employing intelligent transportation systems (ITS); and 4) reducing carbon-intensive travels, by encouraging drivers to shift to other transportation modes, or eliminating singleoccupancy vehicles. 
Puget Sound Regional Council also came up with a rather similar four-part approach. However, it is explained in a more practical way than the U.S. DOT report recommended (PSRC, 2010). Not only to comply with Washington State GHG reduction targets but to satisfy the targets set forward to reducing 50\% of 1990 VMT levels by 2050, the following recommendations are proposed: 1) improving jobshousing balance by reforming land use characteristics to a more compact, transitoriented urban plan; 2) imposing user fees, such as carbon tax, VMT tax, tolling; 3) providing transport options rather than personal cars, such as public transit systems; and 4) supporting advancements in vehicle and fuel technology, which is believed to have the most significant impact on the GHG reduction.

Other researches also tried to categorize approaches using different words, but the overall skeleton of their proposed methods stays the same. National Renewable Energy Laboratory in their 2015 report split their approach under a three-pillar structure, namely cleaner fuels, greener vehicles, and smarter networks (NREL, 2015). Lewis et al. (2016) also stuck with the same three-part strategy and emphasized the importance of setting limits for VMT as an indicator of a smarter transportation network.

It has been estimated that adhering to the Corporate Average Fuel Economy (CAFÉ) Standard which mandates the average fuel economy of new cars to increase to 54 miles per gallon (mpg) by 2040 may result in a 25 to 44 percent reduction in GHGs (PSRC, 2010; Archsmith, et al., 2015). Therefore, the path towards a cleaner vehicle technology is almost paved with acceptable incentives. On the other hand, a challenge in pursuing mobility management plans, which are mainly focused on controlling VMT and increasing population density, are their difficulties in implementation (Moore, et al., 2010; USDOT, 2010; Lewis, et al., 2016). Assuming that political and fiscal issues are soluble, Litman (2013) conducted an analysis and showed how emphasizing comprehensive mobility management approaches may lead to optimal solutions (see Figure 2).

\section{ELECTRIC VEHICLE BASICS}

Technology advancements in car manufacturing unlike mobility management plans are evolving more independently and rapidly. The main reason is that introduction of CAFÉ Standards and alternative fuel vehicles are methods to replace the existing automobile fleet without substantial changes in urban infrastructure. The rest of this paper, therefore, attempts on explaining some details on electric vehicles and their role in mitigating GHG emissions. A brief background on terminologies and electric vehicle status quo is first presented. A literature review on different life cycle analysis (LCA) methods to study the environmental impacts of electric vehicles will be followed after. Compatibility issues around electric vehicles and 
electricity gird will be discussed next. And finally, a few notes about the financial barriers on the way of widespread use of efficient fuel and alternative fuel vehicles wraps up this research paper.

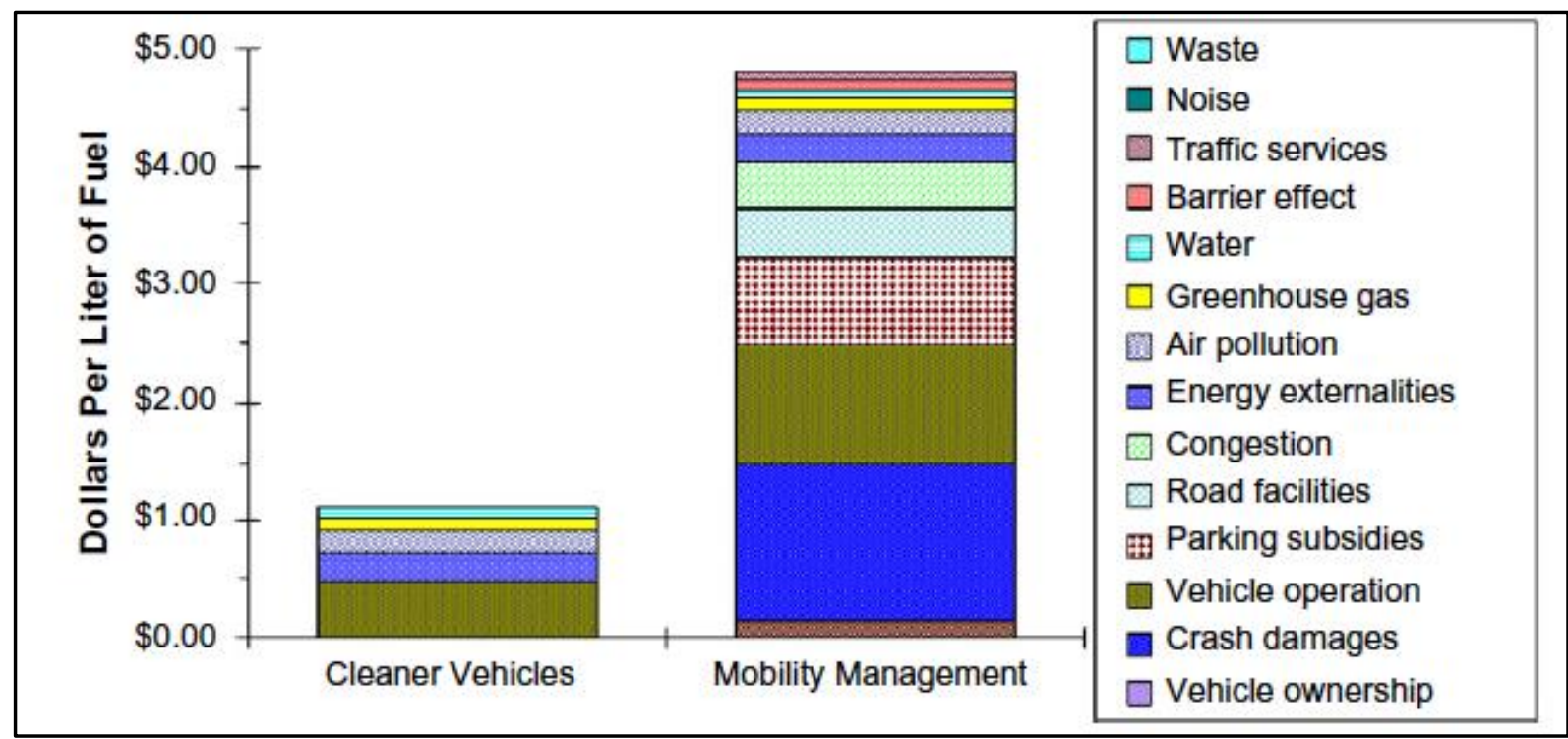

Figure 2 - Comparing benefits of two broad approaches to transportation solutions (Litman, 2013)

\subsection{Terminology}

A list of terminologies mostly used in the automobile realm are given below (Ma, et al., 2012; WSDOT, 2015; Van Mierlo, et al., 2017):

- Internal combustion engine (ICE) vehicle: a majority of conventional vehicles are powered by high-density fuels such as gasoline and diesel.

- Electric vehicle (EV): any vehicle equipped with the ability to consume some of its driving force from the electric grid.

- Hybrid electric vehicle (HEV): refers to an engine that employs both an ICE and an electric drivetrain without relying on the electricity grid.

- Plug-in electric vehicle (PEV): a general term for any vehicle that relies in part on an external source of electricity.

- Battery electric vehicle (BEV): a PEV that solely utilizes a battery charged from the electric grid.

- Plug-in hybrid electric vehicle (PHEV): a PEV that has the characteristics of both an HEV and ICE, having a plug to connect to the electric grid. 
- Fuel cell electric vehicle (FCEV): uses an electric-only motor similar to a $\mathrm{BEV}$, but the battery is charged by combining stored hydrogen gas in the vehicle's tank and the oxygen from the air to produce electricity.

- Vehicles using other alternative fuels such as compressed natural gas (CNG), liquefied natural gas (LNG), and biogas (BG).

\subsection{Background and the Status Quo}

The adoption of EVs depends on three major factors. Limited driving ranges, high purchase prices, and long charging times are among the factors relevant to technology. Governmental incentives and other fiscal decisions in support of EVs are among the policy factors influencing EV market penetration. Lack of appropriate infrastructure for EVs, public acceptability, and dependence on electricity grid characteristics are among the environmental factors affecting EV market diffusion (Yong \& Park, 2017).

However, EVs are believed to penetrate the market faster than presumed before. They are estimated to comprise $20 \%$ of light-duty vehicle sales by $2020,47 \%$ by 2030, and $63 \%$ by 2050 (Schleith, 2015). Norway is among the countries that adopted one of the most aggressive plans to sell only EV and FCEV from 2025. The main reasons that Norway could be capable of adopting such targets are its reliance on renewable energy resources, relatively low electricity rates, and various government incentives that promote the spread of EVs. By 2020, Japan aimed at increasing the penetration of EVs and PHVs by 15 to 20 percent of new car sales. Germany also set goals to increase EVs fleet to 1 million by 2020 by providing a robust infrastructure (Yong \& Park, 2017). In the state of Washington, PEV registrations grew from around 8,000 to 12,000 from 2013 to 2014. The state has also announced the target of 50,000 vehicles by 2020 (WSDOT, 2015).

\subsection{Equivalent MPG}

Proposed by the United States EPA, a metric is required in order to compare efficiencies from conventional ICE vehicles and other alternative fuel consuming vehicles. The issue arises from the fact that electricity or hydrogen and gasoline cannot be scaled into a unit measure such as a gallon. EPA calculations for EVs rely on the assumption that $33.7 \mathrm{kWh}$ of electricity is equivalent to 1 gallon of gasoline (EPA, 2011). One of the main shortcomings of this metric is that it only accounts for the consumption of the on-board energy content in the vehicles' tank or battery (Wikipedia, 2017). Since tailpipe emissions from ICE vehicles are far more than EVs, mpg-equivalent is believed to significantly underestimate EV life cycle emissions. 
Most recently, Manjunath \& Gross (2017) introduced a so-called electric vehicle emissions index (EVEI) to overcome shortcomings from the previously used EPA metric. EVEI is defined as "the ratio of the total GHG emissions of an EV to the total GHG emissions of a GV [gasoline vehicle] or for the same distance with the total GHG emissions of the vehicle considered including the emissions due to production, transportation and consumption of the energy" (Manjunath \& Gross, 2017). They tried to explicitly consider EV-associated emissions from the electricity generation, transmission, and distribution stages to the final consumption thru the vehicle's wheels but ignored the emissions due to manufacturing. Considering the electricity grid source for each state, EVEIs were calculated for the case of a single EV vehicle (Nissan Leaf) for a map of the U.S. depicted in Figure 3.

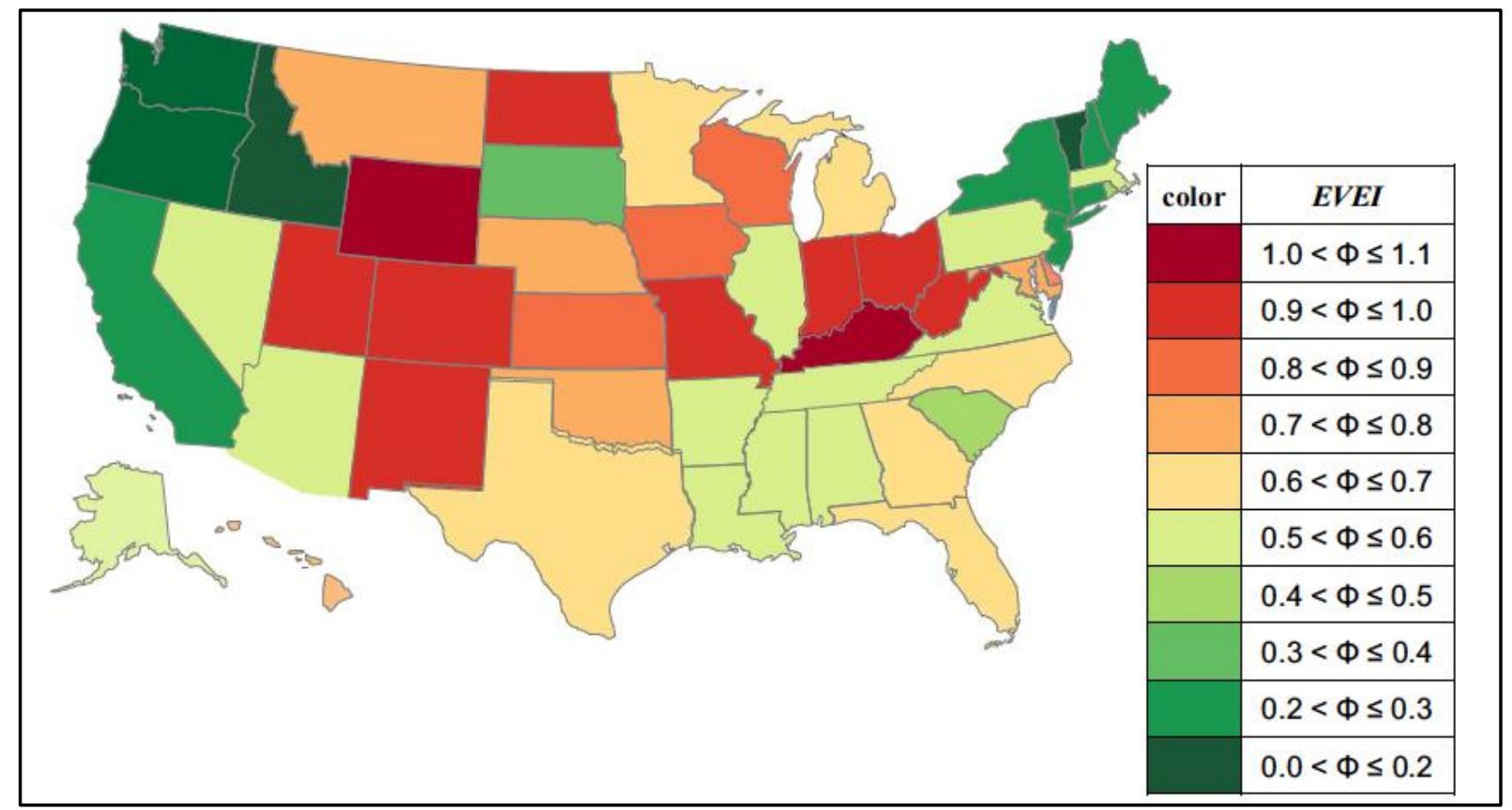

Figure 3 - The variation in EVEI throughout the U.S. with lower values indicate higher efficiencies (Manjunath \& Gross, 2017)

\section{LIFE CYCLE ASSESSMENT}

Life cycle analysis is a robust tool for comparing environmental and monetary costs of different options during their lifetime. Emissions are produced right at the very first stages of manufacturing and continue to maintenance and operation emissions and will not end until the final lifetime and disposal of vehicles, better known as vehicle life cycle (Ma, et al., 2012). For example, there are some nonexhaust local pollutants such as particulate matter from brake, tire, and road abrasions that must be accounted for (Van Mierlo, et al., 2017). Hence, a thorough analysis of how emissions are presented at each stage is necessary. 
In this manner, full life cycle analysis of vehicles can be divided into two major steps of fuel cycle and vehicle cycle. Fuel cycle, also known as well-to-wheels (WTW), deals with the processes for producing raw materials and fuel consumption (Bicer \& Dincer, 2017). WTW itself consists of two subcategories: tank-to-wheels (TTW) which covers the vehicle in-use phase, and well-to-tank (WTT) that covers the production, transmission, and distribution of the fuel (Ma, et al., 2012). Vehicle cycle considers the degradation of vehicle compartments and their associated emissions (Van Mierlo, et al., 2017). Figure 4 schematically defines various phases in a complete vehicle life cycle.

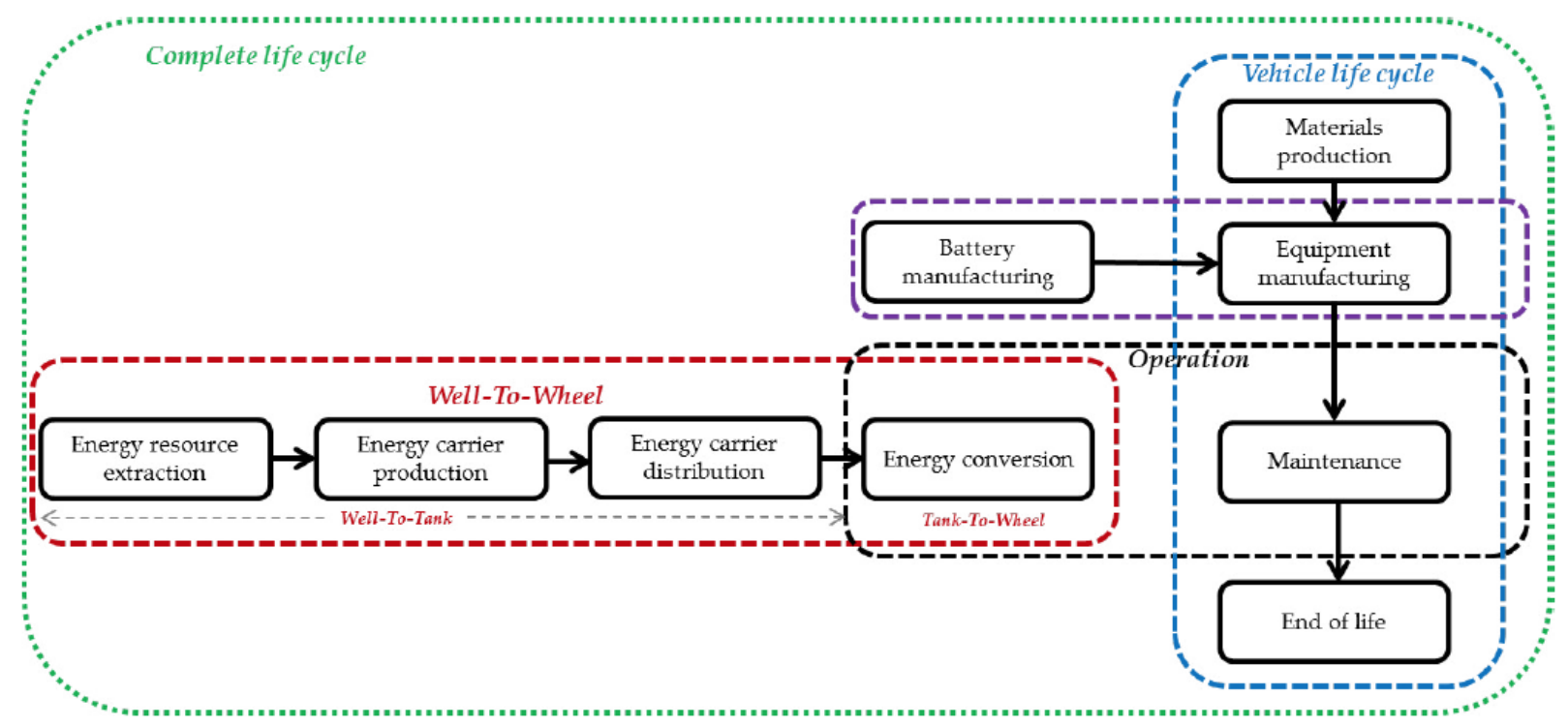

Figure 4 - System boundary and life cycle phases for vehicles (Van Mierlo, et al., 2017)

Tailpipe emissions (TTW) are estimated to represent only 56\% of WTW cycle, and HEVs can save at most around $20 \%$ of WTW emissions comparing to conventional ICE vehicles (Litman, 2013). In another study, GHG emissions associated with the production stage of an EV are shown to almost double when compared to gasoline consuming vehicles, with batteries contribute between 35 to 41 percent of this phase's emissions (Manjunath \& Gross, 2017). Bicer \& Dincer (2017) showed in a WTW analysis that due to manufacturing and maintenance stages, EVs yield higher human toxicity values. They further contend that FCEVs are the most environmentally benign vehicle types when compared to methanol fueled and EVs (Bicer \& Dincer, 2017), which could be the reason why this paper is published in the Hydrogen Energy journal.

Van Mierlo et al. (2017) quantified and compared the life cycle environmental impacts of different vehicle technologies thru a WTW approach. In their study, conventional fossil fuel vehicles were compared to electric, plug-in hybrid, CNG, and BG fueled vehicles in Belgium. The average electricity mix in this country is 
mainly composed of nuclear (around 50\%) and fossil fuels including coal, natural gas, and petroleum (around 30\%). Life cycle emissions were "calculated assuming that the average $\mathrm{CO}_{2}$ emissions of electricity from coal, natural gas, wind and Belgian electricity mix are $1800 \mathrm{~g} / \mathrm{kWh}, 885 \mathrm{~g} / \mathrm{kWh}, 642 \mathrm{~g} / \mathrm{kWh}, 11 \mathrm{~g} / \mathrm{kWh}$ and 190 $\mathrm{g} / \mathrm{kWh}$, respectively" (Van Mierlo, et al., 2017). The results which are shown in Figure 5 indicate that BEV charged with average mix electricity has the lowest emissions, followed by PHEV and BG fueled vehicles. An interesting conclusion from their study is that when coal is used as the main source of electricity generation,

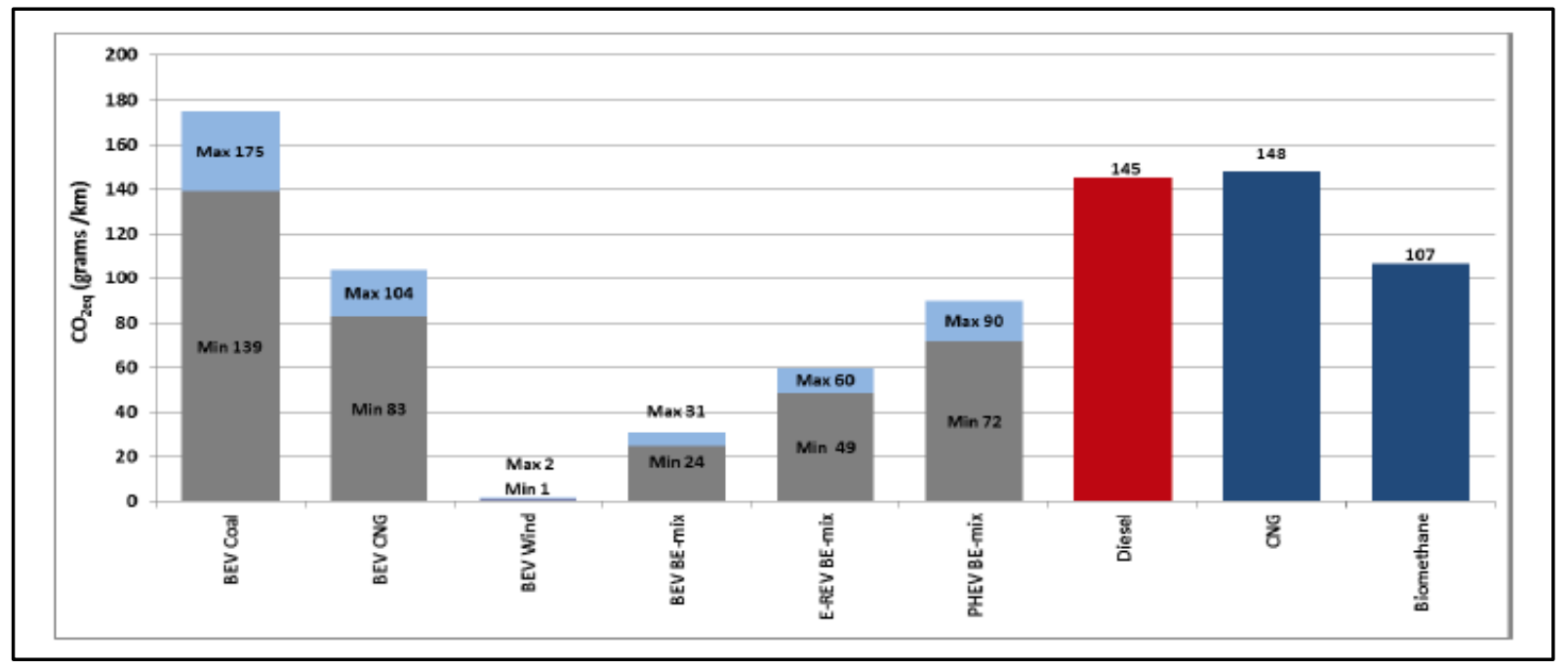

Figure 5 - WTW GHG emissions for different sources of electricity and type of vehicle (Van Mierlo, et al., 2017)

BEVs perform worse than other types of vehicles. However, comparisons between diesel and CNG-fueled vehicles remain questionable from this study.

\subsection{Grid Mix Issues}

It is well known that EVs produce nearly zero tailpipe emissions and hence can reduce GHG levels from urban atmospheres. However, emissions would be shifted towards suburban areas where most of the electric power plants are located. Depending on the sources of energy used to generate electricity, emissions from EVs may vary by a great deal. Generally, electricity is generated from a mix of sources during the daytime, or even within each month of a year (Van Mierlo, et al., 2017). As a result, the charging behavior of EV users can become a key parameter when estimating life cycle emissions from these vehicles (Anair \& Mahmassani, 2012). This section summarizes several researches that have been carried out around these issues.

Ma et al. (2012) studied the effect of marginal grid intensity as opposed to the average grid intensity. They concluded that when considering marginal grid intensity, overall life cycle emissions from BEVs and HEVs are identical. The main 
reason mentioned is that fossil fuels are commonly used to produce marginal electricity. Since off-peak hours usually occur at nighttime, and EVs are being charged at that time, caution should be taken when analyzing life cycle emissions for EVs (Manjunath \& Gross, 2017). However, when grid GHG intensity is sufficiently low, BEVs can save significant amounts of pollutants comparing to ICE vehicles (Ma, et al., 2012).

Weldon et al. (2016) undertook a study to shed light on how user behavior in EV charging and the fuel mix of electricity production can impact the life cycle emissions in Ireland. They found that nighttime charging tends to impose the largest environmental impact. Instead of assuming any fuel mix of electricity production, their study made use of real charging data obtained from data loggers within Ireland along with real-time data on the $\mathrm{CO}_{2}$ emissions of the electric grid. Because a number of small generators would be operating during nighttime instead of large plants, the efficiency in producing electricity is remarkably lower at night (Weldon, et al., 2016). This fact together with the user behavior in charging their EVs during nighttime worsens the situation and may affect the environmental viability of EVs. However, it is also worth noticing that coal and natural gas are the main components of power plant sources in Ireland which makes the conclusions of this study highly location dependent.

In another study, Archsmith et al. (2015) investigated the effect of fuel mix on estimating total fuel cycle emissions in the U.S. They also accounted for the effect of temperature regimes on the efficiency of charging and discharging batteries. In their conclusion, EVs would result in GHG reductions by up to 20 percent relative to their ICE counterparts in most states, while in some states EVs have the potential to produce more emissions. It is hence closely related to the electric grid composition and the ambient temperature, with colder temperatures having an adverse effect on the efficiency (Archsmith, et al., 2015). Another study used the mpg-equivalent concept while accounting for electricity grid mix for a breakdown of different regions throughout the U.S. (Anair \& Mahmassani, 2012). Assuming EV efficiency of $0.34 \mathrm{kWh}$ per mile, they concluded that $45 \%$ of states are prone to have lower emissions than a 50-mpg gasoline vehicle, $38 \%$ of states between 41 to $50 \mathrm{mpg}$, and the rest between 31 to $40 \mathrm{mpg}$. Figure 6 illustrates how different mpg-equivalents are estimated for each region in the U.S.

\subsection{Battery Issues}

GHG emissions associated with battery manufacture cause the vehicle life cycle emissions to be higher for BEVs than ICE vehicles. Consequently, technologies in battery composition and production have been advancing and gained much attention recently. However, an obstacle that is encountered from a battery perspective is that 
they tend to age rapidly (Van Mierlo, et al., 2017). As batteries degrade and become out of order, they should be discarded and replaced and this will demand consideration for more detailed life cycle analysis (Ma, et al., 2012). This fact would further give rise to the influence of recycling stages on the overall score of life cycle emissions for BEVs. A review of the available literature shows that a common assumption over the use of batteries is that a large-scale recycling procedure will be followed in the near future that helps BEVs to gain more environmental benefits.

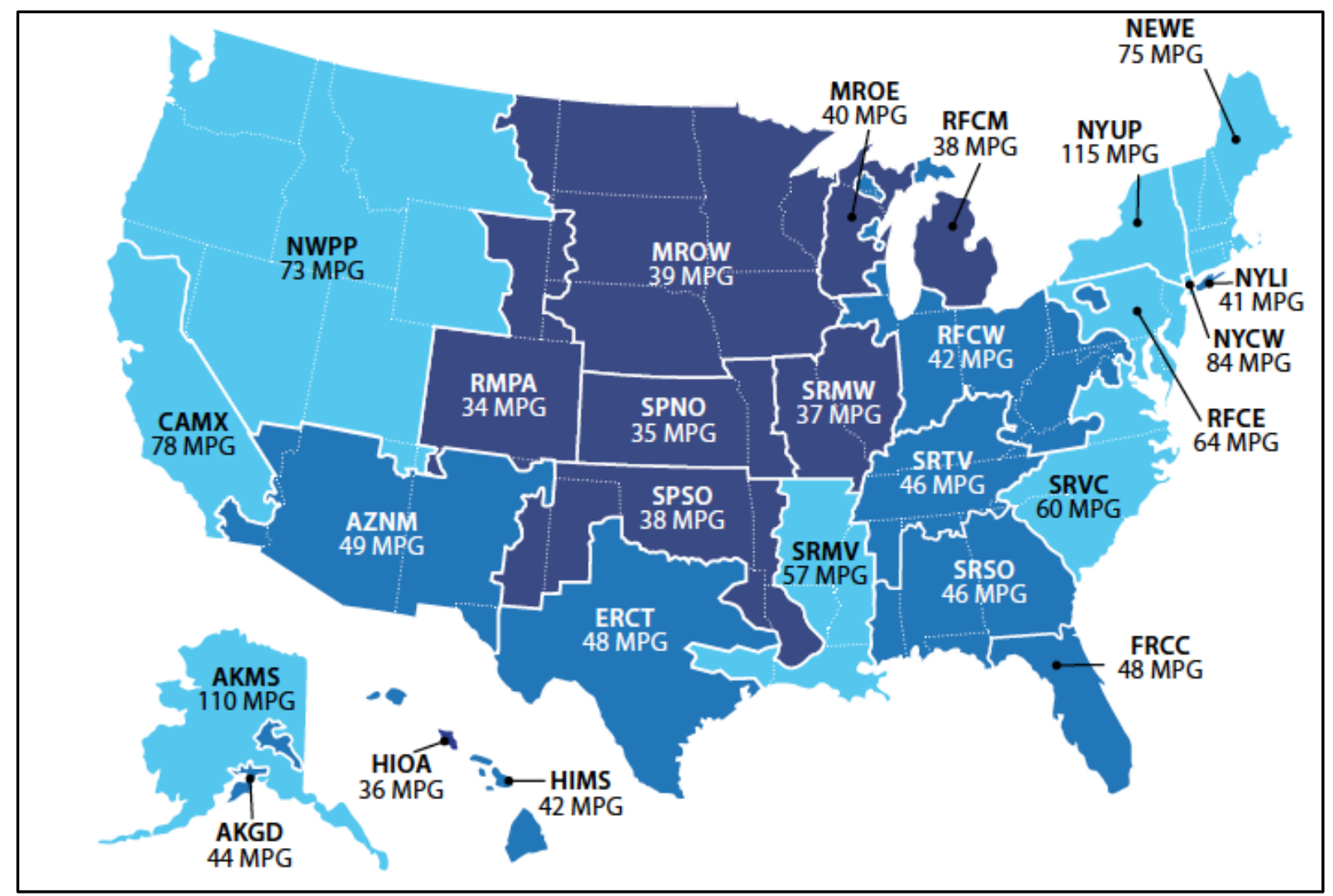

Figure 6-Electric vehicle global warming pollution ratings and gasoline vehicle emissions equivalent by region (Anair \& Mahmassani, 2012)

Another issue concerning batteries is their long recharging time which depends on their size, the amount of charge required, and the type of charging equipment (WSDOT, 2015). In this regard, three levels of charging are available: level 1) is a 120 -volt charger capable of adding 3 to 5 miles of range per hour; level 2) is a 240volt charger that can add 10 to 20 miles of range per hour; and 3) DC fast charging, which is able to add 60 to 80 miles of range in about 20 minutes. As a rule of thumb, the shorter it gets to charge a battery, the more severe the degradation rate will be. However, battery technology is a fast-growing industry and it is expected that future batteries would have mile ranges way higher than ICE vehicles. 


\section{FUEL TAX REVENUE}

Ennis (2009) stated that $61 \%$ of all the transportation budget in the 2007-09 biennium was earned from fuel taxes. Another study noted that $76 \%$ of the total investments in the transportation sector are derived from fuel taxes (Meyer, et al., 2010). Consequently, these facts give rise to a paradox that if people fill their vehicles' tank with less or even no gas, the fuel tax revenue would shrink down noticeably. The shortcoming in transportation budget is translated into either a lack of sufficient funds for maintenance and preservation purposes or budgets for transportation services would further diminish (Climate Action Team, 2008; Frost, 2017). Moreover, since a large chunk of budgets is dedicated to roads and parking facilities, there would not be many financial resources left to enhance public transit infrastructure.

The impact of EVs may not be sudden, but in 15 to 20 years they might have a notable influence on fuel tax revenue. Additionally, the costs of annual highway construction and maintenance have experienced an ever-increasing trend recently which calls for allocating a great portion of the transportation budget (Schleith, 2015). To compensate for the predicted shortage in fuel tax revenues, and considering the fact that federal gasoline tax remained constant from its 1993 level of 18.4 cents per gallon, other alternatives must be devised (Langer, et al., 2017). U.S. Congress in 2015 passed a \$305 billion five-year bill called Fixing America's Surface Transportation (FAST) Act mainly due to the reason mentioned above (Schleith, 2015).

Other options to substitute for the shortage of fuel tax are taxation based on VMT and traffic congestion, road tolling, and increased direct taxes and surcharges on vehicle purchases. VMT tax in particular gained more attention since it may act as a twofold strategy. Not only has VMT tax the ability to compensate for fuel tax, but it can also encourage city planners to fulfill mobility management strategies. Langer et al. (2017) found out that "a VMT tax designed to increase highway spending \$55 billion per year increases annual welfare by $\$ 10.5$ billion or nearly $20 \%$ more than a gasoline tax" (Langer, et al., 2017). Three benefits are believed to associate with a VMT tax instead of a fuel tax, in that it can be fair in treating all drivers the same, produce a stable revenue, and also be flexible to adjustments (Schleith, 2015). However, implementing VMT-based taxation can shift the burden towards the lowincome population, and may also face political and institutional hindrance.

\section{SUMMARY AND CONCLUSION}

The transportation sector is responsible for one-third of all GHG emissions worldwide, and around two-thirds are attributed to the road vehicle fleet. Two distinct approaches exist to tackle the high consumption of fossil fuels within the 
transportation sector. Enhancements in vehicle fuel efficiency and utilizing alternative fuel vehicles fall into the broad category of cleaner vehicles. The other approach is best known as mobility management strategies, which target to alleviate the use of personal cars and shift transport to less polluting modes. However, an integrated approach that considers the concurrent effects of cleaner vehicles and wiser travel decisions seems to result in optimal solutions.

Penetration of electric vehicles into the automobile market has gained special attention recently. Technology advancements, battery manufacturing, in particular, are believed to be the most powerful driving force of this movement. Several studies have been carried out in an attempt to reasonably compare various types of electric and hybrid to conventional fuel combustion vehicles. The major tool to achieve a meaningful comparison is a cradle to junkyard life cycle analysis. The ultimate goal of these analyses would be to come up with a simple metric similar to a mile per gallon for conventional vehicles so as to clarify the differences in a simple unit.

However, complexities in performing a thorough life cycle assessment have tightened the hands of many researchers to stay within only a part of this whole cycle. As a result, small assumptions when conducting analysis may lead to considerable differences in conclusions. On one hand, tailpipe emissions from electric vehicles are observed to be significantly lower (near zero for battery electric vehicles) than internal combustion engine vehicles. On the other hand, life cycle investigations indicated that battery electric vehicles emit more GHGs during production and manufacturing stages.

One of the primary areas of conflict when evaluating electric vehicle's life cycle is the dependency on the electric grid as the source of energy. Electricity generation can produce as much emissions as the transportation sector does. Hence, the cleanliness of electric vehicles is hinged on the source of energy used to generate electricity. In regions where renewables are the main contributors to electricity generation, electric vehicles can far outpace internal combustion vehicles. On the contrary, in places where dirtier sources of energy, such as coal and natural gas, are in use, care must be taken when comparing electric and high-density fuel consuming vehicles.

There are also some other barriers to mainstream electric vehicle adoption. High purchase cost, limited vehicle range, scarce charging infrastructure, inappropriate taxation, lack of consumer awareness, lack of understanding incentives, and difficulties to establish charging equipment in homes are among factors that need to be addressed (WSDOT, 2015; Manjunath \& Gross, 2017; Palencia, et al., 2017). To overcome these obstacles, continued investments are required to enhance electric vehicles' performance and cost, incentives should be clearly defined for consumers 
and manufacturers, and a reliable and widespread charging infrastructure must be deliberately prepared (Anair \& Mahmassani, 2012). After the initial penetration of electric vehicles, however, a change in policy directions from monetary support to non-monetary support seems to be essential (Yong \& Park, 2017).

\section{REFERENCES}

Anair, D. \& Mahmassani, A., 2012. State of Charge; Electric Vehicles' Global Warming Emissions and Fuel-Cost Savings across the United States, Cambridge, MA: Union of Concerned Scientists.

Archsmith, J., Kendall, A. \& Rapson, D., 2015. From Cradle to Junkyard: Assessing the Life Cycle Greenhouse Gas Benefits of Electric Vehicles. Research in Transportation Economics, Volume 52, pp. 72-90.

Bicer, Y. \& Dincer, I., 2017. Comparative Life Cycle Assesment of Hydrogen, Methanol and Electric Vehicles from Well to Wheel. International Journal of Hydrogen Energy, Volume 42, pp. 3767-3777.

Climate Action Team, 2008. Reducing Greenhouse Gas Emissions and Increasing Transportation Choices for the Future.

EIA, 2017. Annyal Energy Outlook 2017.

Ennis, M., 2009. State's Mandate to Reduce Driver Mobility Threatens Revenue for Transportation Projects. Policy Note, January.

EPA, 2011. New Fuel Economy and Environment Labels for a New Generation of Vehicles: U.S. Environmental Protection Agency (EPA).

EPA, 2015. Global Greenhouse Gas Emissions Data. [Online] Available at: https://www.epa.gov/ghgemissions/global-greenhouse-gasemissions-data [Accessed November 2017].

Frost, M., 2017. The Road Usage Charge: To Impose a Tax on Every Mile You Drive. Policy Brief.

Langer, A., Maheshri, V. \& Winston, C., 2017. From Gallons to Miles: A Disaggregate Analysis of Automobile Travel and Externality Taxes. Journal of Public Economics, Volume 152, pp. 34-46.

Lewis, R., Zako, R., Biddle, A. \& Isbell, R., 2016. Reducing Greenhouse Gas Emissions from Transportation: Lessons from West Coast States. Transportation Resrach Board, pp. Paper Number: 16-4983.

Litman, T., 2013. Comprehensive Evaluation of Energy Conservation and Emission Reduction Policies. Transportation Research Part A, Volume 47, pp. 153-166. 
Ma, H. et al., 2012. A New Comparison Between the Life Cycle Greenhouse Gas Emissions of Battery Electric Vehicles and Internal Combustion Vehicles. Energy Policy, Volume 44, pp. 160-173.

Manjunath, A. \& Gross, G., 2017. Towards a Meaningful Metric for the Quantification of GHG Emissions of Electric Vehicles (EVs). Energy Policy, Volume 102, pp. 423-429.

Meyer, M. D. et al., 2010. Washington State DOT's Sustainability Efforts.

Moore, A. T., Staley, S. R. \& Poole, R. W., 2010. The Role of VMT Reduction in Meeting Climate Change Policy Goals. Transportation Research Part A, Volume 44, pp. 565-574.

NREL, 2015. Sustainable Transportation: National Renewable Energy Laboratory.

Palencia, J. C. G., Ostuka, Y., Araki, M. \& Shiga, S., 2017. Scenario Analysis of Lightweight and Electric-Drive Vehicle Market Penetration in the Long-Term and Impact on the Light-Duty Vehicle Fleet. Applied Energy, Volume 204, pp. 14441462.

PSRC, 2010. Transportation 2040: Toward A Sustainable Transportation System: Pouget Sound Regional Council.

Schleith, K., 2015. Implications of Electric Vehicles on Gasoline Tax Revenues.

USDOT, 2010. Transportation's Role in Reducing U.S. Greenhouse Gas Emissions: U.S. Department of Transportation.

Van Mierlo, J., Messagie, M. \& Rangaraju, S., 2017. Comparative Environmental Assessment of Alternative Fueled Vehicles using a Life Cycle Assessment. Transportation Research Procedia, Volume 25, pp. 3435-3445.

Weldon, P., Morrissey, P. \& O'Mahoney, M., 2016. Environmental Impacts of Varying Electric Vehicle User Behaviours and Comparisons to Internal Combustion Engine Vehicle Usage - An Irish Case Study. Journal of Power Sources, Volume 319, pp. 27-38.

Wikipedia, 2017. Miles Per Gallon Gasoline Equivalent. [Online] Available at: http://en.wikipedia.org/wiki/Miles_per_gallon gasoline equivalent [Accessed 27 November 2017].

WSDOT, 2015. Washington State Electric Vehicle Action Plan: Washington State Department of Transportation.

Yong, T. \& Park, C., 2017. A Qualitative Comparative Analysis on Factors Affecting the Deployment of Electric Vehicles. Energy Procedia, Volume 128, pp. 497-503. 